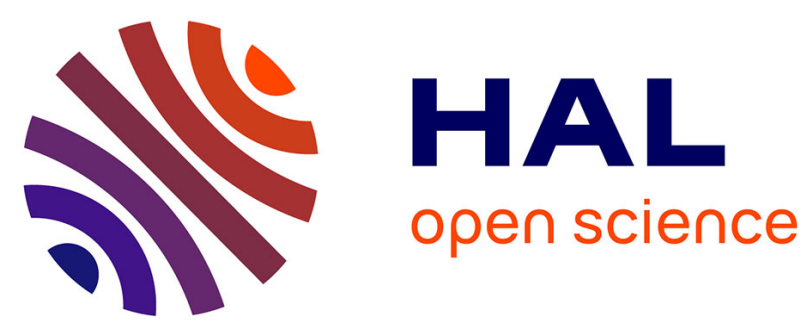

\title{
Unsteady flow rate simulations methodology for identification of the dynamic transfer function of a cavitating venturi
}

Artem Marie-Magdeleine, Regiane Fortes Patella, Nicolas Lemoine, Nicolas Marchand

\section{To cite this version:}

Artem Marie-Magdeleine, Regiane Fortes Patella, Nicolas Lemoine, Nicolas Marchand. Unsteady flow rate simulations methodology for identification of the dynamic transfer function of a cavitating venturi. CAV 2012 Symposium, 2012, Singapour, Singapore. 10.3850/978-981-07-2826-7_020 . hal-02510568

\section{HAL Id: hal-02510568 \\ https://hal.science/hal-02510568}

Submitted on 13 Aug 2020

HAL is a multi-disciplinary open access archive for the deposit and dissemination of scientific research documents, whether they are published or not. The documents may come from teaching and research institutions in France or abroad, or from public or private research centers.
L'archive ouverte pluridisciplinaire $\mathbf{H A L}$, est destinée au dépôt et à la diffusion de documents scientifiques de niveau recherche, publiés ou non, émanant des établissements d'enseignement et de recherche français ou étrangers, des laboratoires publics ou privés. 


\section{Unsteady flow rate evaluation methodology for identification of the dynamic transfer function of a cavitating Venturi.}

\author{
Artem MARIE-MAGDELEINE \\ CNES, Evry, France
}

\author{
Nicolas LEMOINE
}

Snecma, Vernon, France

\author{
Regiane FORTES-PATELLA \\ LEGI, Grenoble, France
}

\author{
Nicolas MARC HAND \\ GIPSA, Grenoble, France
}

\begin{abstract}
SUMMARY
The development of new rocket turbopumps makes it necessary to study different phenomena occurring during cavitation, such as auto-oscillations that can cause the POG effect and damage the rocket structure if they occur at the structural eigenfrequency. This is why an experimental facility is currently being developed in the Cremhyg laboratory in Grenøble, France in $\bullet$ rder to perform dynamic characterization -f different cavitating devices to define the general identification methodology. The work presented in this paper serves the purpose to test this methodology on a simulation case of the cavitating Venturi computed with the IZ code. The principle of the IZ code is presented in the second paragraph. The first step of the methodology consists of evaluating pressures and mass flow rates at the inlet and the outlet of the cavitating profile and the next steps aims at estimating the dynamic transfer function of the cavitating Venturi. For this purpose, the Kinetic Differential Pressure method was chosen and introduced and its robustness towards evaluation uncertainties is evaluated in the third paragraph. Next, the numerical simulation with the IZ code gives the empirical transfer function results from the precise inlet and outlet pressure data which is later compared with the transfer matrix coefficients obtained with the Kinetic Differential Pressure method using the standard identification procedures such as the Empirical transfer function evaluation and the user-made AutoRegressive Moving Average e Xøgenous algørithm.
\end{abstract}

\section{INTRODUCTION}

During the development of a new liquid propellant rocket engine the knøwledge of dynamic transfer functions of cavitating turbopumps is primordial in order to correctly assess the risk of $\mathrm{POG}$ phenomenon occurrence and to possibly prop»se a corresp»nding solution of an anti-POGO correction. Several studies on this topic were carried by every major space agencies [1-4]. In France, CNES (Centre national d'Etudes Spatiales) and Snecma are currently working in partnership with LEGl, Gipsa-lab and CremHyg laboratories in Grenoble on building a hydrødynamic test facility to perform identification of transfer functions of different cavitating devices. In $\bullet$ rder to ensure that the tests g properly, several methods of unsteady flow rate evaluation and signal processing need to be considered. [5-6]

This facility includes devices allowing pressure and flow rate fluctuations in the domain from 5 to $50 \mathrm{~Hz}$ as well as instrumentation capable of measuring these fluctuations. Different ptical (LDV, PIV, PDI, LIF), acustic (ADV), electromagnetic, thermoanemometric (hot film, hot wire), magnetic resønance and ionization methøs were considered [6, 8-12]. Finally, the method using Kinetic Differential Pressures (KDP) [13] was chosen as both the simplest to implement and enøugh accurate. The perfermance of this method is presented in this article. This meth allows deducing flow rate fluctuations from the unsteady pressure evaluations and thus to obtain all the infonnation the operator needs to identify the dynamic transfer matrix of a cavitating device [3]:

$$
\left(\begin{array}{l}
\tilde{P}_{s} \\
\tilde{Q}_{s}
\end{array}\right)=\left(\begin{array}{ll}
Z_{m} & Z_{\ell} \\
Z_{c} & Z_{M}
\end{array}\right)\left(\begin{array}{l}
\tilde{P}_{e} \\
\tilde{Q}_{e}
\end{array}\right)
$$

All variables are taken in the Fourier frequency domain. The superscript $\sim$ means that fluctuating quantities are taken, but it will be $\bullet$ mitted for the remaining frequency-d main fonnulae. Befiore applying KDP method for experimental data processing, a numerical method was developed in order to test and to evaluate the methodology of the mass flow rate restitution and of the dynamic transfer matrix identification. This article describes this methødoløgy and presents its first application results.

\section{OBJECT OF STUDY}

The unsteady flow reconstitution simulation and the system identification algorithms will be tested on the cavitating Venturi CFD computations perfonned by the $2 \mathrm{D}$ unsteady code "IZ", which has been developed in our team with the support of the CNES-Centre National d'Etudes Spatiales. The code solves the Reynolds Averaged Navier-Støkes equations for a homogeneus fluid; it applies the $k-\varepsilon$ RNG turbulence model associated to a barotropic approach to the cavitation modeling. The numerical code is widely described in [7], and has been 
previously validated under different cavitating flow configurations.

The studied Venturi (Fig.1) is coupled to the pipes at the inlet and the outlet of the system (Fig.2). The circuit impedance is modeled by a 1D hydro-elastic model that solves the Allievi's equations.

$$
\frac{\partial p}{\partial t}+u \frac{\partial p}{\partial x}+\rho \alpha^{2} \frac{\partial u}{\partial x}=0 \quad \frac{\partial u}{\partial t}+u \frac{\partial u}{\partial x}+\frac{1}{\rho} \frac{\partial p}{\partial x}+C_{f} \frac{u|u|}{2 D}=0
$$

where $u$ is the speed of the fluid flow, $p$ is the pressure, Cf is the friction factor, $\mathrm{D}$ the pipe diameter, $\rho$ the water density, $x$ the coordinate and a the sound speed in the pipe, which is defined from the sound speed in the water, pipe wall thickness $e$ and Young modulus $\mathrm{E}$ :

$$
a=\frac{c}{\sqrt{1+\frac{\rho_{\text {water }} c^{2} D_{i}}{e E}}}
$$

These equations are solved by using the Method of Characteristics MOC. Head losses are modelled by the diaphragm approach [19].

The different boundary conditions during this study are the total reflection (pressure node) or the total absorption at the outlet (no-reflecting boundaly conditions [18]). The mass flow is imposed at the inlet. This choice is a primordial part of the system identification procedure. Typically the imposed flow rate fluctuations are either a sum of several sinusoids or a chimp signal. Depending on the inlet excitation signal, different data post-treatment algorithms may be applied in order to determine the dynamic transfer matrix terms.

Calculations presented in this paper concem cold water, a mean flow rate equal to $15.5 \mathrm{~L} / \mathrm{s}$ and inlet mean sigma coefficient value of about 2.4. The fluctuating pressure and flow rates are taken by 3 pressure sensors placed in the inlet pipe and 3 in the outlet pipe equidistantly (Fig. 2).

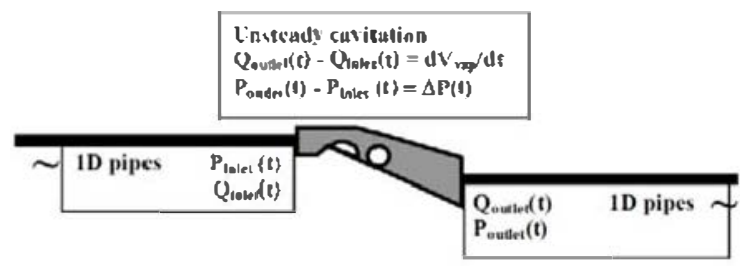

Figure 1: Venturi pipe coupling

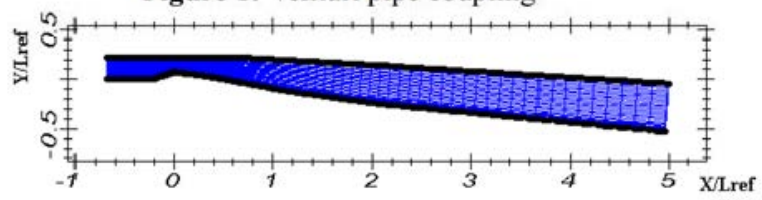

Figure 2: Venturi geometry

\section{KDP BACKGROUND THEORY}

In this part equations characterizing the KDP method are described. They are at applied in the case of a simple duct in order to evaluate the accuracy and the robustness of the method when sensor data is polluted with a noise term.

\section{General equations}

Three equidistant points at the inlet pipe and three nodes at the outlet one are chosen as the positions of the pressure sensors. The pressure data at these nodes is used to estimate the unsteady flow rate in the pipe using the acoustic wave equations. The pressure signal is composed of one wave travelling in one direction and another wave travelling in the opposite direction $[5,6,13]$ :

$$
p(x, \omega, t)=\rho\left(A e^{i \omega\left(t-\frac{x}{a}\right)}+B e^{i \omega\left(t+\frac{x}{a}\right)}\right)
$$

Let $k=\frac{2 \pi f}{a}$. Hence the values read on the pressure sensors can be written the following way after a Fourier transform, and the system of equations is solved in order to obtain the values of ascending and descending waves $\mathrm{A}$ and $\mathrm{B}$ and for the sound speed a:

$$
\begin{gathered}
P_{1}(f)=\rho g\left(A(f) e^{i k l}+B(f) e^{-i k l}\right) \\
P_{2}(f)=\rho g(A(f)+B(f)) \\
P_{3}(f)=\rho g\left(A(f) e^{-i k l}+B(f) e^{i k l}\right) \\
\frac{P_{1}+P_{3}}{2 P_{2}}=\frac{e^{i k l}+e^{-i k l}}{2}=\cos \left(\frac{2 \pi f l}{a}\right) \\
a=\frac{2 \pi f l}{\arccos \left(\left\|\frac{P_{1}+P_{3}}{2 P_{2}}\right\|\right)}
\end{gathered}
$$

The value of the sound speed $a$ is to be taken at the frequency $f$ where the signal spectral density is important to be more precise. The expressions of the unsteady pressure and the unsteady mass flow rate at every coordinate $x$ of the pipe can be estimated using these acoustic wave equations:

$$
\begin{aligned}
& P(x, f)=\rho g\left(A(f) e^{-i k x}+B(f) e^{j k x}\right) \\
& Q(x, f)=\frac{\rho g S}{a}\left(A(f) e^{-i k x}-B(f) e^{i k x}\right)
\end{aligned}
$$

It seems important to notice that the values of $\mathrm{P}$ and $\mathrm{Q}$ could be taken elsewhere from the measuring sections; hence the KDP method can also be used to extrapolate the unsteady pressure and mass flow rate data eloser to the inlet and the outlet of the cavitating device to be characterized.

In order to reconstruct time-domain data of the unsteady flow rate an inverse Fourier transfonm may be taken. However, for the identification purposes only the frequency domain data taken at the modulation frequency is needed. Firstly, several calculations have been perfonmed on a ID line. At one end of the line the flow rate was modulated by a user as a sum of sine waves or as a chirp signal, and on the other end of the hydraulic line a totally reflecting limit condition was implemented. The CFL condition was sct to bc equal to 1 . The test section had a length of $12 \mathrm{~m}$ split into 41 nodes separated by $30 \mathrm{~cm}$, the initial sound speed was $928 \mathrm{~m} / \mathrm{s}$, and thus the time step dt was $3,2.10^{-4} \mathrm{~s}$ which is $0.01 \mathrm{~T}_{\text {ref. }}$. The position of the points giving the pressure information P1, P2, P3 are typically the $5^{\text {th }}, 20^{\text {th }}$ and $35^{\text {th }}$. However, the acoustic wave equations allow extrapolating the values of pressures and mass flow rates closer to the duct boundaries, i.e. at the $1^{\text {st }}$ and the $41^{\text {st }}$ nodes. The results of the sound speed estimation and the flow rate reconstruction from the pressure nodes data showed to be in a good agreement with the originally implemented values. For the sound speed, typical estimation errors were about $1 \%$ and for the flow rate the amplitude of a reconstructed signal may present the difference up to $3 \%$ with the simulated signal. The comparison between the original simulated flow rate and the reconstructed values are given at the Fig. 3 and 4: 


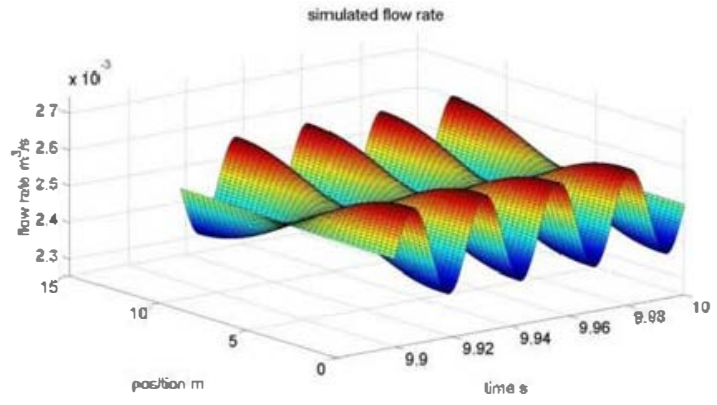

Figure 3: Simulated flow rate

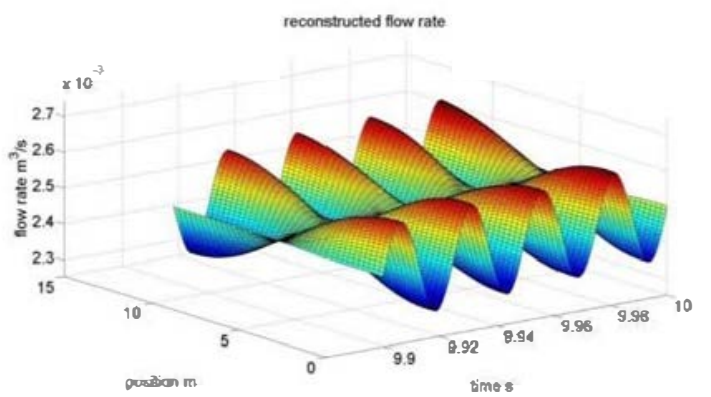

Figure 4: Recenstructed flow rate

The small differences between the tw surfaces may be explained by the head losses taken into account for the simulation $(\lambda=0.019)$ but not taken into account in the acoustic wave equation used for mass flow rate reconstitution. The Rout Mean Square error is about $10 \%$ between the frequency domain signals of the simulated and the reconstructed fl. $\bullet$ rates.

Transfer matrix evaluation method

Once the inlet and outlet pressure and mass tlow rate trequency domain data is obtained, it is possible to evaluate the coefficients of the transfer matrix. As there are in all 2 inlet and 2 outlet variables, it is necessary to perfom a series of tests with the linearly independent inlet frequency-domain data vectors $\left(\mathrm{P}_{\mathrm{e} 1}, \mathrm{Q}_{\mathrm{el}}\right)$ and $\left(\mathrm{P}_{\mathrm{e} 2}, \mathrm{Q}_{\mathrm{e} 2}\right)$. This can be achieved through different procedures. Firstly, the inlet mass flow rate amplitude variation fixed by the user does not imply inlet pressure fluctuations to vary propertionally. The other way to preceed is to change the pipeline boundary conditions, that is for instance to test the pressure node condition totally reflecting acoustic waves and the "free outlet" condition without any reflection. Moreover, the system linearity can be tested with at least 3 noncollinear input data vectors $\left(\mathrm{P}_{\mathrm{e}}, \mathrm{Q}_{\mathrm{e}}\right)$. The expressions of the transfer matrix coefficients are the following:

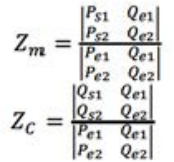

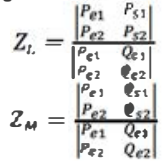

This evaluation method is called the Empirical Transfer Function Evaluation, or ETFE. It gives satisfactory results if the signal to noise rati is high enøugh. Otherwise, other methods may be used, e.g. auto-recursive methods such as ARMAX [14, 15], which will be presented later in the article. KDP Method robustness evaluation

The pressure sensørs used may present high uncertainty values. The possible evaluation errors may come from intemal causes (sensør calibration, numerical noise, linearization errøs, and pipe vibrations) as well as from external ones (electromagnetic pøllution from neighboring facilities) [16]. This is why it is important to test the algorithm robustness in case when the signal to noise ratio is low

To this extent, a random Gaussian noise variable is added the simulated pressure signal, uncertainty propagation is studied and the obtained results are compared with those corresponding to the 'clean' simulation.

Propagation from $P(t)$ to $P(j \omega)$

The error on the time-domain signal is noted $\eta(t)$ and the one on the frequency-domain signal is $\epsilon(j \omega)$. The time-domain error is a Gaussian zero-centered white noise uncorrelated with $\mathrm{P}(\mathrm{t})$, and its amplitude may be estimated if the operator knows the possible error causes. The values of time-domain and frequency-domain errors are linked by the Parseval Formula for the Discrete Fourier Transform:

$$
\frac{T}{t_{1}} \sum_{t_{\xi}=0}^{T}\left|\eta\left(t_{i}\right)\right|^{2}=\sum_{\omega=0}^{z / \tau_{2}}\|E(j \omega)\|^{2}
$$

As $t_{1}$ is the time step and T the total simulation time, $1 / T$ is the frequency step and $l / t_{1}$ the maximum frequency vector value. $\eta$ is a zero-mean noise, when the number of samples $\mathrm{N}=\frac{r}{i_{1}}$ increases, the relation between the standard deviations $\sigma_{\eta}$ and $\sigma_{\epsilon}$ is $\sigma_{\epsilon}=\sigma_{\eta} \sqrt{N}$. On the other side, $P_{i}(\ell)$ are typically sums of sine waves, and the amplitude of the spectral density function of $\mathrm{P}_{\mathrm{i}}$ at modulated frequencies are directly propertional to the samples number $N: P_{i}\left(j \omega_{m o d}\right)=\frac{N}{2 j}$. Hence, the noise to signal ratio at the modulated frequency $f_{\bmod }$ is proportional to $\frac{1}{\sqrt{N}}$ when $\mathrm{N}$ increases:

$$
\frac{\epsilon_{i}\left(j \omega_{\text {mod }}\right)}{P_{i}\left(j \omega_{\text {mod }}\right)} \propto \frac{1}{\sqrt{N}}
$$

That means the longer the time-domain acquisition is, the higher the accuracy of the frequency-domain data $P(j \omega)$ is. Propagation from $P\left(j \omega_{\text {mond }}\right)$ to $Q\left(j \omega_{\text {mrod }}\right)$

At first, the uncertainty propagation on the sound speed $\epsilon_{a}$ needs to be estimated as a function of the freguency domain functions taken at the modulation frequency:

$$
\frac{\epsilon_{a}}{a}=\frac{\epsilon_{2}}{2 P_{2}}-\frac{2 \epsilon_{2}-\epsilon_{1}-\epsilon_{3}}{2\left(2 P_{2}-P_{1}-P_{3}\right)}
$$

Using the uncertainties propagation law it is possible to calculate the standard deviation of the sound of the speed evaluation, supposing the errors $\epsilon_{1}, \epsilon_{2}, \epsilon_{3}$ independent:

$$
\sigma_{a}^{2}=\frac{\left(\sigma_{\epsilon 1}^{2}+\sigma_{\epsilon 3}^{2}+\left(\frac{P_{1}+P_{3}}{P_{2}}\right)^{2} \sigma_{\epsilon 2}^{2}\right) 4 n^{2} f^{2} l^{2}}{\left(4 P_{2}^{2}-\left(P_{1}+P_{3}\right)^{2}\right) \cdot \arccos ^{2}\left(\frac{P_{1}+P_{3}}{2 P_{2}}\right)}
$$

Numberswise an error on the sound speed is less than $5 \%$ if the initial time-domain pressure evaluation errer $\eta(t)$ is $7 \%$ of measurement range. The expression of the err or on the mass flow rate may be retrieved from the acoustic wave equation:

$$
\begin{gathered}
\epsilon_{Q}=Q \frac{\epsilon_{\sigma}}{a}(\operatorname{ctg} g(k l) .(k l)-1)+\frac{s j k \frac{\epsilon_{Q}}{a}}{a \cdot \sin (k l)}\left(P_{2} \sin (k(l+x)) \cdot(l+x)-P_{1} \sin (k x)\right) \\
-\frac{j s}{a} \frac{\epsilon_{1} \cos (k x)-\epsilon_{2} \cos (k(x+l))}{\sin (k l)}
\end{gathered}
$$

To quantify the possible errors on the mass flow rate a MonteCarl simulation was performed with 1000 runs on the pipeline presented in the previous paragr aph. For every simulation, each sensor data was artificially polluted with the white noise. The 
Fig. 5 illustrates the error distribution on the mass fløw rate at the modulated frequency $Q\left(j \omega_{\text {mod }}\right)$ :

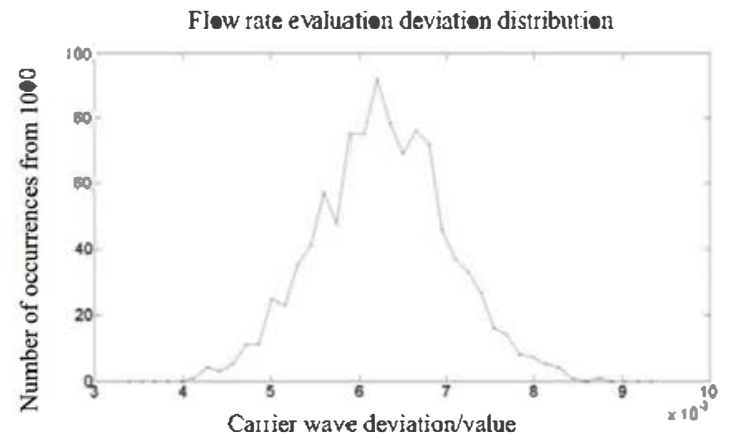

Figure 5: Mass flow rate error distribution

It can be seen at the diagram abve that the estimated error may be decomposed into the systematic error of $0.6 \%$ of the flow rate fluctuation amplitude and int the random епто with standard deviation of $0.1 \%$. The variation of the input random noise standard deviation has only influence on the random error.

Propagation to the empirical transfer finction result

The evaluation errors committed on the pressure and flow rate freguency-domain data will imply uncertainties on the final result of the transfer matrix coefficients. The exact fonnulation of the uncertainty propagation to the transfer matrix coefficients are presented below:

$$
\frac{\epsilon_{Z m}}{Z_{m}}=\frac{\left|\begin{array}{ll}
Q_{e 2} & \epsilon_{P s 2} \\
Q_{e 1} & \epsilon_{P s 1}
\end{array}\right|+\left|\begin{array}{ll}
P_{s 1} & \epsilon_{\varphi e 1} \\
P_{s 2} & \epsilon_{Q e 2}
\end{array}\right|}{\left|\begin{array}{ll}
P_{s 1} & Q_{e 1} \\
P_{s 2} & Q_{e 2}
\end{array}\right|}-\frac{\left|\begin{array}{ll}
P_{e 1} & \epsilon_{Q e 1} \\
P_{e 2} & \epsilon_{e 22}
\end{array}\right|+\left|\begin{array}{ll}
Q_{e 22} & \epsilon_{e e 2} \\
Q_{e 1} & \epsilon_{p_{e 1}}
\end{array}\right|}{\left|\begin{array}{ll}
Q_{e 1} & Q_{e 1} \\
P_{e 2} & Q_{e 2}
\end{array}\right|}
$$

The three other transfer matrix coefficients are expressed mutatis mutandis using the ETFE fonnulae. In the case when the user is not satisfied with the method robustness towards white noise, a user-made auto-recursive multiple input noise resistant algorithm ARMAX has been developed for this study.

\section{RESULTS AND DISCUSSION}

In a first series of simulations the Venturi is taken coupled with $3 \mathrm{~m}$ ducts (with $\mathrm{I}$ nodes) at the inlet and outlet. The small number of nodes makes it impossible to apply the KDP method on this simulation. Thus, the values of pressure and mass flow rates are taken at the inlet and outlet of the Venturi tube in order to test the proposed identification methods.

The Fig. 6 and 7 show the system linearity domain. Pøint $I$ is the evaluation of the transfer matrix using inlet mass flow rate fluctuations of $1 \%$ and $2 \%$ of amplitude, point 2 uses $2 \%$ and $3 \%$ and so on.

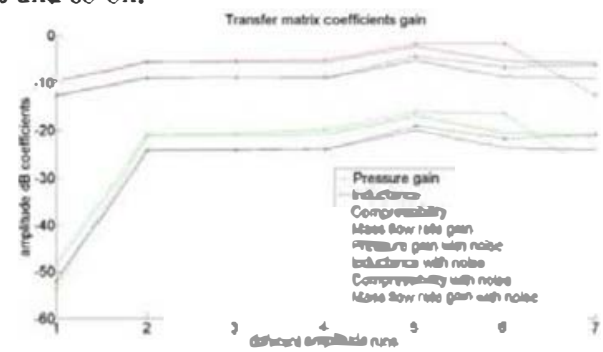

Figure 6: Gain linearity

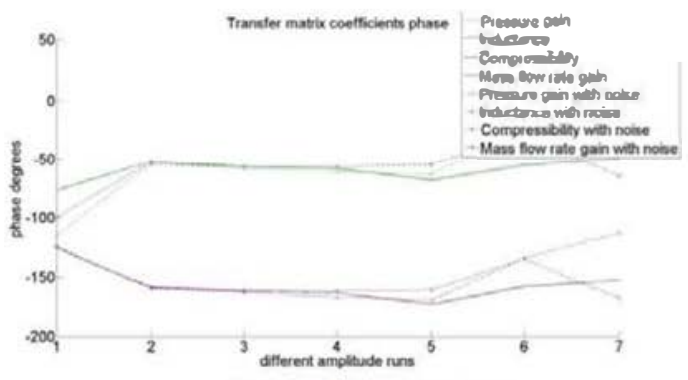

Figure 7: Phase linearity

$\mathrm{T}_{\text {ref }}$ is $0.032 \mathrm{~s}$ for this simulation. The tests were nm with the same frequency of $5 \mathrm{H} z$. These diagrams show that for the amplitudes between $2 \%$ and $5 \%$ of flow rate modulation the gain and the phase of the system remains the same. Even with the strong input noise ( $7 \%$ of measurement range) the transfer matrix coefficients remain quasi-constant.

The next simulations show the Bode diagram of the frequency transfer matrix of the cavitating Venturi obtained by the empirical estimation formulae ETFE (Fig. 8 and 9)

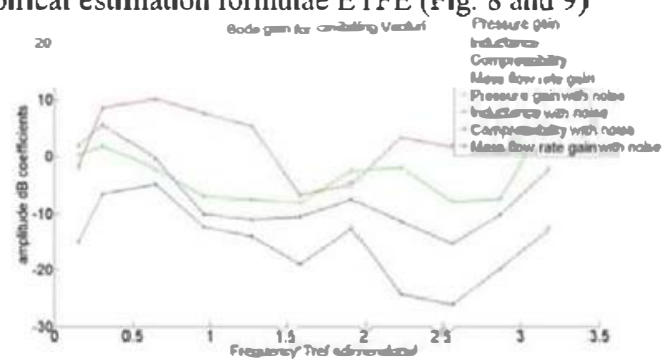

Figure 8: B॰de gain for cavitating Ventur

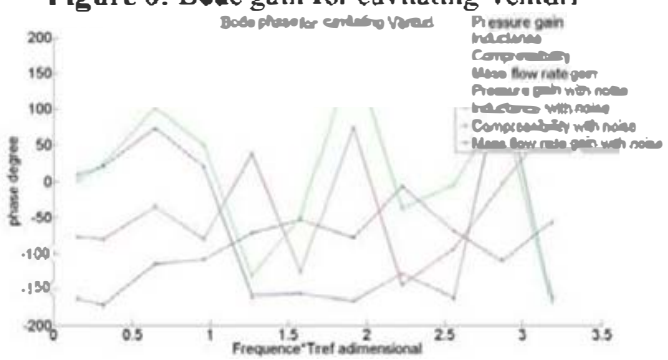

Figure 9: Bode phase for cavitating Venturi

The input noise has a less than I dB influence on the final ETFE result. Hence the frequency per frequency method is very accurate to estimate the transfer matrix ceefficients both for the gain and the phase. The drawback of this method is that the values of the transfer function are only known at the modulated frequencies. This is why it seems logical to try an identification of a transfer function for another type of input signal in order to make the identification process quicker. To perform this task, a chirp-type signal was used, because it presents a very large spectral density which is corresponding to the operator's needs. The next simulations (Fig. 10 and 11) were performed for a down-chirp signal $\sin (\sqrt{t})$. The spectral density of the input signal is contained between 0 and $0.2 \mathrm{~Hz}^{*} \mathrm{~T}_{\text {ref. }}$. Accrding the graphs below, the results give more data points using only two simulations with linearly independent input vectors, however it is less accurate than frequency by frequency tests, with noise 
crrors reaching $S$ to $10 \mathrm{~dB}$, even if most of the points secm very accurate. The phase crrors seem however important for the inductance and compressibility, reaching 20 degrecs.

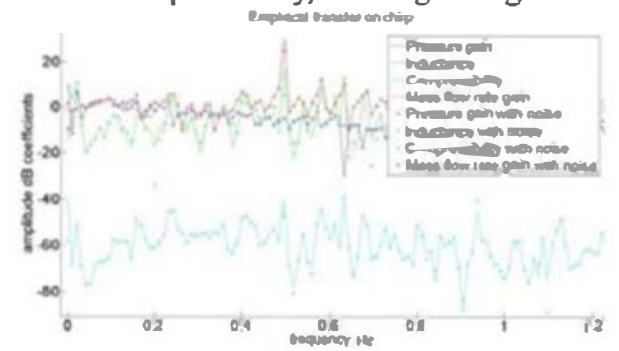

Figurc 10: Bode gain for a down-chirp

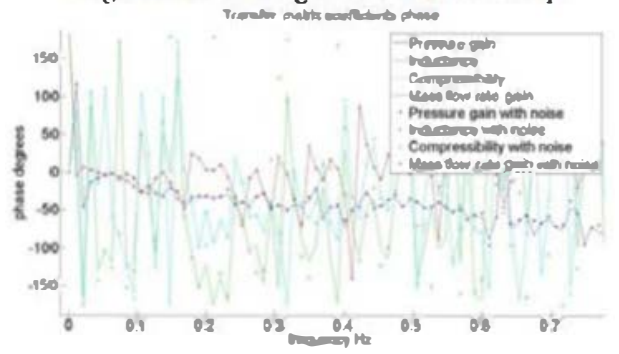

Figure 11: Bode phase for a down-chisp

In order to make the transfer matrix calculation from the ETFE input signal even more accurate and noise-proof the ARMAX (Auto-Regressive Moving Average Exogenous) identification method was implemented for this MIMO (Multiple Input Multiple Output) case $[14,15]$. The chosen algorithm uses least mean squares by Kalman filter approach and forgetting factor. Only one simulation is necessary to perform the identification on the spectral domain set by the input which was chosen to be an up-chirp signal $\left(\sin \left(t^{2}\right)\right)$

The last scrics of simulations of cavitating Venturi combined the mass flow rate reconstruction by KDP method, ETFE and ARMAX identification methods. Thus it is possible to evaluate the accuracy of the KDP method on the test case and the accuracy of the ARMAX identification method applied on the reconstructed pressurc and flow rates, which will not be possible during experiments. The simulation was performed on the up-chirp signals with totally reflecting or totally absorbing limit conditions. The Fig. 12 and 13 allow us to compare the ETFE of the four transfer matrix coefficients on the reference inlet-outlet signals, with the ETFE on pressure and tlow rate signals reconstrucled by the KDP method at the inlet and the outlet and with the transfer matrix coefficients obtained by user-made auto-recursive algorithm ARMAX. The eiror on the sound speed reconstitution was of $1 \%$ on both the inlet and the outlet lines compared to the initially implemented value. The results show that the KDP method in this case gives up to $10 \mathrm{~dB}$ стоrs for the majority of the frequencies on the transfer function identification. For the phase, the reconstructed ETFE values may present up to 90 degrees error. It has to be noticed that the zeros and poles of the sysicm determined by the ARMAX algorithm arc lying in the entire frequency domain, even if the input signal presented no power density associated to the concerned frequency. This is why sometimes the user needs to define a very high order on the system (the $30^{\text {dt }}$ order was used for this simulation) which makes it difficult to link the model to any physical representation.

\section{CONCLUSION}

In this paper the precision of the KDP method to evaluate unsteady mass flow rate and its robustmess towards pressurc evaluation uncertaintics was evaluated. This algorithm can be used to find the sound of the speed value, and to estimate the value of the mass flow rate fluctuations, thus making it possible to perform the whole identification procedure. The frequency per frequency tests proved to be the most accurate, but also to need the biggest amount of experience data. The study of a chirp signal need much less data but is also less accurate. Finally, the KDP method scems enough precise to implement it to the experimental lacility. The present work will be pursued especially to adapt the recursive algorithm part to the operator needs. The simulations presented in this paper had for purpose to develop the methodology to work with the experimental results that will come from the test facility. The tests began in April 2012.

\section{ACKNOWLEDGMENTS}

The authors would like to express their sincere gratitude to Fabio Carvalho (LEGl) who provided his assistance for several simulations with the IZ code, as well as to A. Pintiau, A. Kemilis, J. Toutin (Snecma) for their help with KDP method of the unsteady flow measurement, to J.J. Martinez (Gipsa-lab) for the explantation of the auto-rccursive identification methods, and finally to $\mathrm{O}$. Brugiere (LEGI) for his advice about the uncertainties propagation. We would especially like to thank the Centre National d'Etudes Spatiales for the IZ simulation code.

\section{NOMENCLATURE}

$P$ - fluid static pressurc, frequency domain

$\mathrm{Q}$ - mass flow ratc, frequency domain

Z-impedance

p - fluid static pressure, time domain

II - fluid velocity, time domain

$\mathrm{C}_{5}=\lambda_{4}-$ friction coelficients

a - speed of sound in the pipe

c-spred of sound in the water

D - pipe diameter

e - pipc wall thickness

$\mathrm{E}$ - pipc matericl Young modulus

$\mathrm{S}$ - pipe section

$\mathrm{x}, \mathrm{dx}$ - coordinate, space step

t, dt - time, time step

g- gravity

$\mathbf{k}$ - wavenumber

I - distance between pressure evaluations

f - frequency

$\mathrm{T}$ - total simulation timc

$\mathrm{N}$ - number of samples

Greek letters

$\rho$ - fluid density

$\omega$-pulsation 

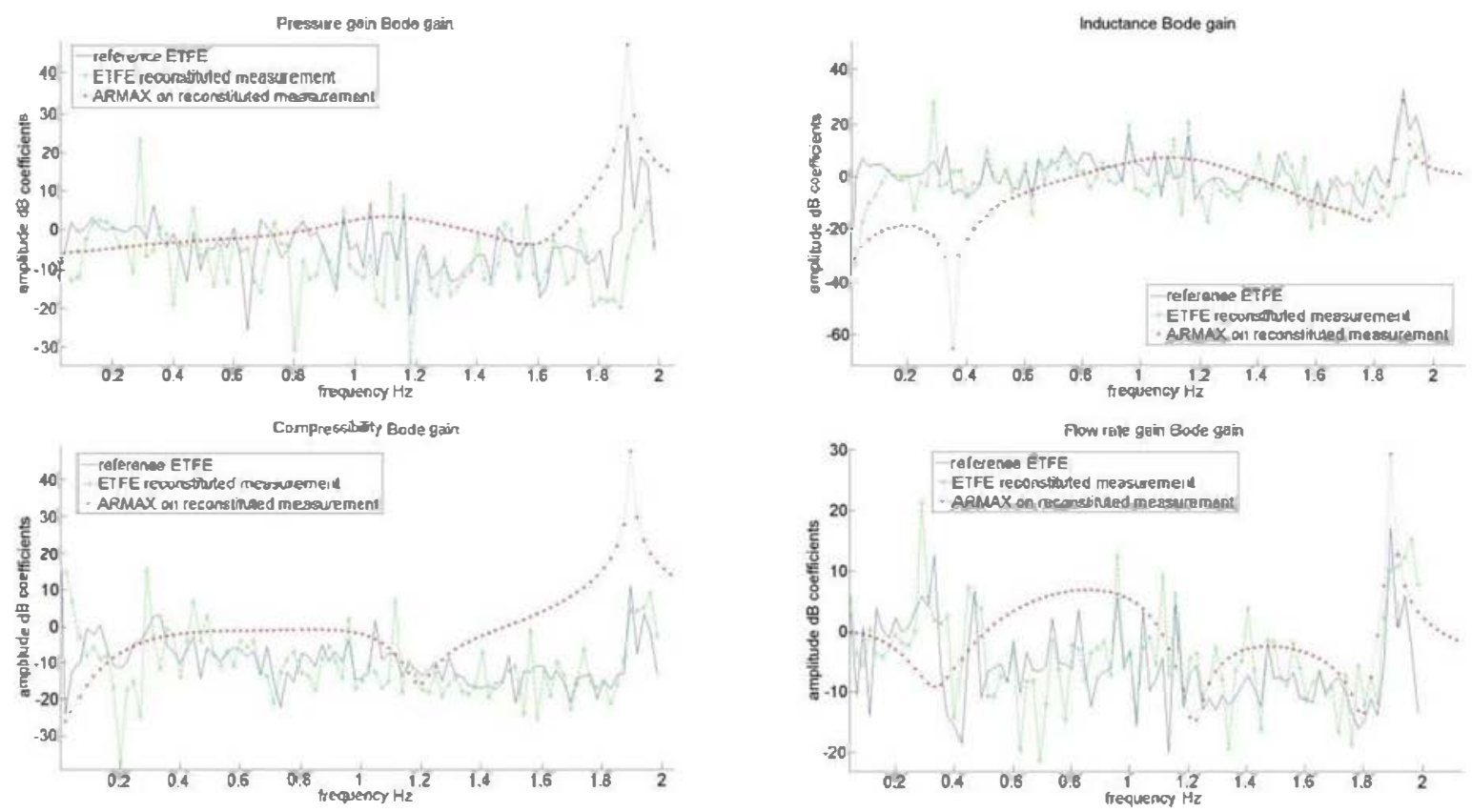

Figure 12: Bode gain diagrams
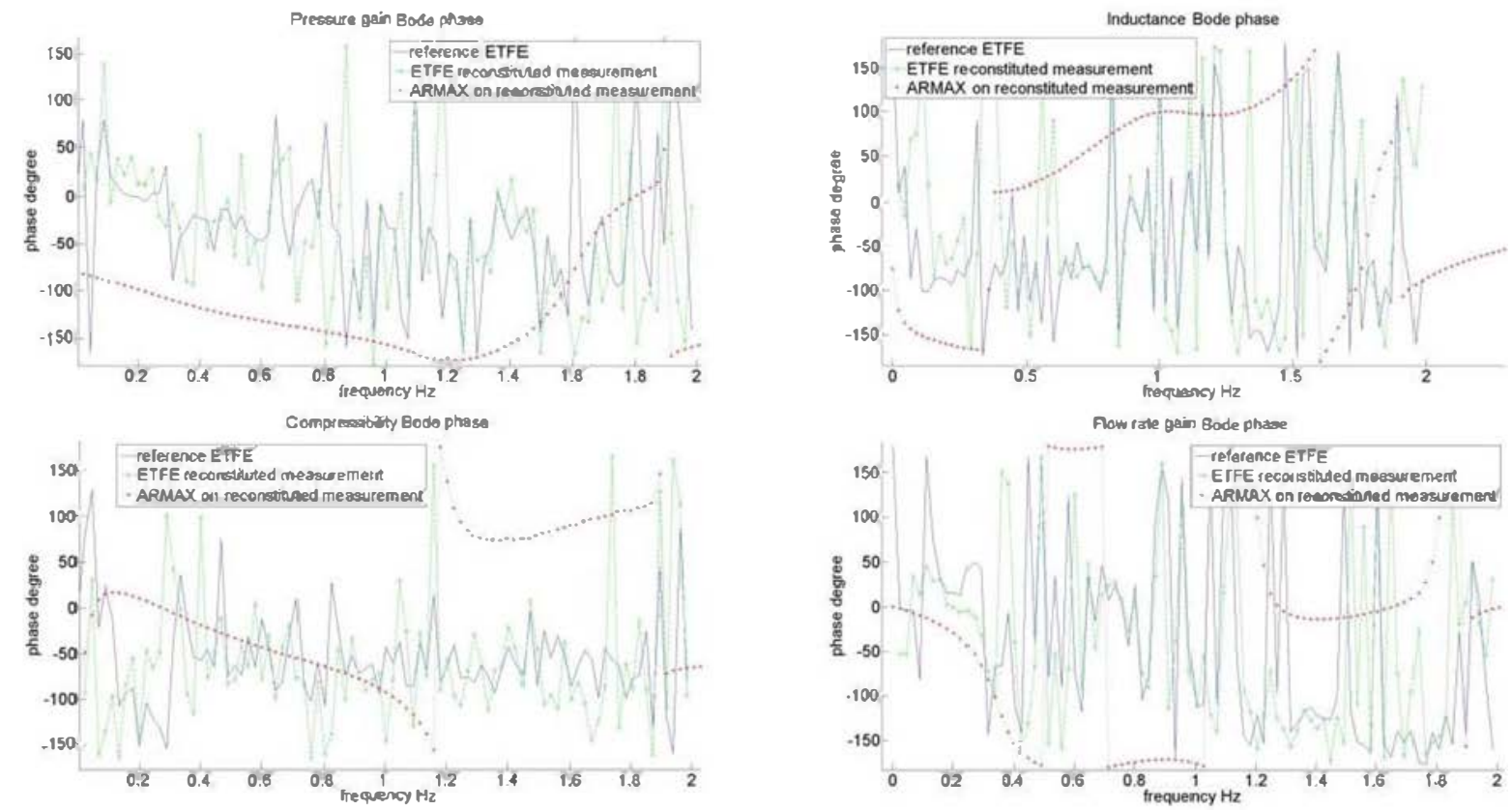

Figure 13: Bode phase diagrams

$\sigma$-standard deviation

$\eta$ - time domain noise on pressure signal

$\epsilon$ - frequency domain noise on pressurc signal

Superscript

$\sim$ - fluctuating quantities

Subscripts

$\mathrm{m}$ - pressure gain
L - inductance

C-compressibility

M - Mass flow gain

i - inner

$\mathrm{e}-$ inlet

$\mathrm{s}$ - outlet

$1,2,3$ - pressure data nodes 
l, 2 - non-collinear vectors

mod - modulated

a - speed of søund

- mass flow rate

$\mathrm{P}$ - pressure

$Z$-impedance

$\epsilon$ - fieguency dømain noise on pressure signal

ref - reference

\section{REFERENCES}

[I] Ren H., Ren G., Rong K., Ma D., Zhang J., A non-linear model of the simulation of the pogo vibrations in liquid rackets, Structure and environment engineering, vol. $33 \mathrm{~N}^{\circ} 3,2006$ (in Chinese)

[2] T. Shimura, K. Kamijo, Cavitation induce flow vibration of liquid oxygen pumps for rockets, JSME $N^{\circ} 87-1318 B$ (in Japanese)

[3] C.E. Brennen, A.J. Acosta, Dynamic transfer function for a cavitating inducer, Journal of Fluids engineering vol.98, 1976

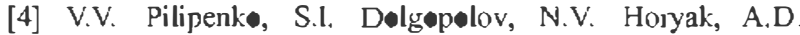
Nikølaev, Mathematical mødelling of løngitudinal oscillations of liquid propellant rocket during bipartial instability of the dynamic system LPRE - rocket structure, Airspace Technics and Technology', $N^{\circ} 10$ (57), 2008 (in Russian)

[5] J.F. Lauro, A. Boyer, Transmission matrix and hydroacoustic sources of a centrifugal pump at very low load, La Hoville Blanche, $\mathrm{N}^{\circ} 374,1998$ (in French)

[6] J.J. Dordain, M. Marchetti, Transfer matrices of hydraulic systems. Theretical and experimental study, Airspace Reseurch N¹-1974 (in French)

[7] Coutier-Delgosha O., Reboud J-L., Delannoy Y. (2003), "Numerical simulation of the unsteady behaviour of cavitating flows", Int. J. for Numerical Meth. In fluids, Vol. 42, pp. 527548.

[8] NG, S.L., Brennen, C., Experiments on the dynamic behavier of cavitating pumps, Journal of Fluids Engineering, vol. 100,1978
[9] Lefebvre, P.J., Durgin, W.W., A transient electromagnetic flowmeter and calibration facility, Journal of Fluids Engineering 12/v $1.112,1990$

[10] Choi, J.-S., McLaughlin, D.K., Thompsøn, D.E. Experiments on the unsteady field and noise generation in a centrifugal pump impeller, Journal of sound and vibration 263 (2003) pp. 493-516

[II] Elkins, C.J., Alley, M.T., Magnetic resonance velocimetry applications of magnetic resonance imaging in the measurement of fluid motion, Experiments in Fluids, $\mathrm{N}^{\circ} 43$, 2007

[12] Katys, G.P., Methods and apparatus to measure parameters of unsteady themal processes, ed. Mashgiz, Moscow, 1959, part 4, ch.3, (in Russian)

[13] Kashima, A., Lee, P.J., Nokes, R., Numerical errors in discharge measurements using the KDP method, Journal of hydranlic reseurch, iFirst 2011, pp 1-7, DOI: $10.1080 / 00221686.2011 .638211$

[14] Fassois, S.D., MIM LMS-ARMAX identification of vibrating structures - part l: the method, Mechanical systems and signal processing (2001) I4(4), pp. 723-735

[15] Moore, S.M., Lai, J.C.S., Shankar, K., ARMAX modal parameter identification in the presence of unmeasured excitation - I: Theretical background, Mechanical sysiems and signal processing 21 (2007) pp. 1601-1615

[16] Priel, M., Incertitudes de mesure et tolerances, Dossier Techniques de l'Ingénieur, r285, 1999 (in French)

[17] S. Rubin, "An interpretation of transfer function data for a cavitating pump," in Proceedings of the 40th AIAA Joint Propulsion Conference, Fort Lauderdale, Fla, USA, 2004, AIAA-2004-4025.

[18] Thompsøn K.W. (1987), "Time dependent bøundary conditions for hyperbolic systems", Joumal of Computational Physics, Vol. 68, pp. 1-24 and (1990), "Time dependent bøundary conditions for hyperbolic systems, Part II", Jøumal of Computational Physics, Vol. 89, pp. 439-46I.

[19] F Longatte, J L Kueny (1999), "Analysis of rotor-statorcircuit interactions in a centrifugal pump", Proceedings of the 3rd ASMEJSME Jøint Fluids Engineering Conference 